\section{B A Institute of \\ YK Business Administration \\ 光 \\ Karachi \\ Leadership and Ideas for Tomorrow}

Business Review

Volume 8 Issue 2 July-December 2013

$7-1-2013$

\title{
The changing HRM practices through CMP model (a comparative case study on American and Asian companies)
}

Nadir Ali

Keyline University, UAE

Follow this and additional works at: https://ir.iba.edu.pk/businessreview

Part of the Business Intelligence Commons, and the Training and Development Commons

\section{c) (7)}

This work is licensed under a Creative Commons Attribution 4.0 International License.

\section{Recommended Citation}

Ali, N. (2013). The changing HRM practices through CMP model (a comparative case study on American and Asian companies). Business Review, 8(2), 142-161. Retrieved from https://doi.org/10.54784/ 1990-6587.1292 
https://ir.iba.edu.pk/businessreview/vol8/iss2/11

DOI: https://doi.org/10.54784/1990-6587.1292

Business Review - Volume 8 Number 2

July - December 2013

\title{
CASE STUDY
}

\section{The Changing HRM practices through CMP model (A Comparative Case study on American and Asian Companies)}

\author{
Nadir Ali \\ Keyline University, UAE
}

\begin{abstract}
The paper aims to report on the role of HR managers with special reference to changing management practices by proposing a model named CMP (Changing Management Practices) for modern companies. This will help organizations to set their directions in the most appropriate manner. The main purpose of this case study is to analyze the parameters proposed in the model and apply them on the sampled companies from American and Asian contexts. The study reports as a comparative case study as it is the best choice to address such parameters mentioned in the CMP model. Research suggests that companies no longer have a choice when it comes to adopting modern changes. If they do not accept these changes, they will lag behind in this hypercompetitive global scenario. . Companies are supposed to handle the overload of information, customer changing choices, employees' motivational level and adopt modern methods of corporate activities. Such practices are well identified by HR managers as they are considered important organizational icons and must be managed like an organizational wheel of coordination, collaboration and changing modern management practices. The practical implication of this paper will be on HR managers who will apply the parameters mentioned in the model. HR managers can utilize the CMP model to make their companies more competitive. Modern managers will learn from the success of the companies and will adopt the ways recommended in this study. This paper is a comparative case study for academic and practical domains. It will benefit all HR managers, students and Business Management faculty.
\end{abstract}

JEL Classification: M12, M14

Key words: Changing Management Practices, The Role of HR managers, Modern Organizations and CMP Model.

\section{Introduction}

Organizations are always in search of finding good people with interpersonal skills, social acceptance and commercial minds. In this regard, HR managers are the main icons to be utilized and help others to do the same. Today's varied Change Management models, OD processes \&Strategic HRD functions are supposed to be smartly applied and HR managers are the responsible personnel to measure that all such practices are complied with organization needs. This research paper highlights the importance of such factors and this study aims to help HR managers see their roles in the bigger picture. The CMP model in this study is logically complied with TQM, BPR, OD practitioners and Changing Management Models for modern companies. All sampled companies follow all models but CMP is the important model for them. The author has 
suggested this model (CMP) as a tool that helps run the company smoothly. This research got across and explored all the factors in detail and found that changing management practices are required when it is the need of the hour in terms of culture, change, analytical approach, coping up with IT, management styles and role of HR managers in modern organizational domain. The role of HR managers is highlighted in almost every aspect mentioned in the model.

Today's HR managers have more tasks to ensure that everything is right as it must be not only for the company and its employees but for the customers as well to enhance organizational productivity. As identified by Olson, 2008 "Lower productivity and morale, missed objectives, wasted time, wasted money \& higher employee turnover mean big costs of failure for the organization" (Olson, 2008). HR Managers will always be important icons because of the increasing scope of HR management. As Aberg said Even HR departments are downsized, HRM seems to become increasingly important (AbergAas, 2005). The HR manager, in changing management practices is considered an important agent to innovate and develop resources and intellectual capital to compete with modern companies. As Beer and others supported that "Managing Human Assets (Beer, et al, 1984) emphasized the importance of innovating in HRM practices in order to "build a relationship between the organization and its employees that will pass the tests of greater competition and the shrinking economic pie" (Beer, et al 1984:7). Most of the companies are stuck in many approaches to develop yardsticks to get all employees motivated but selection criteria needs to be focused. As Devanna said "HRM is very important thing, its areas as suggested by Devanna, Fombrun\&Tichy (1984),Four generic functions for HRM, Selection, Appraisal, Development \&Research"The ultimate goal should be to improve performance, both for the organization and for the individual. HR needs to help executives understand that if they do not accurately understand the strengths and weaknesses of the cultures they create, they will have a harder time achieving their organizational objectives. By focusing on training and development efforts, HR will help employees to think, act and behave in the desired manner. .

\section{Literature Review}

Today's fast paced changing technological age has brought lots of changes and the responsibilities of Marketing managers, Finance manages, MIS managers \&HR managers have also been changed into various modern categories. Such influence has also affected the role of HR managers to design new strategies to cope up with modern changes and workforce diversity in particular. This study has a special focus on HR managers' role in modern organizations with continuous changes to HRM activities. The Role of HR managers in changing management practices is changing due to the different ways of executing HR activities based on globalization, information flow and information technology updates in coordination, communication and faster work processes. According to Richard Change, author of the Passion plan at work, HRM focuses mainly on HR research \& development system, union \& labor relations, employee assistance \& employee compensation. Whereas he says, HRD, includes career development as helping individuals, aligning career planning, organizational development as helping groups initiate and manage change, and also mentions training and development as designing, developing and delivering training to ensure people are equipped to do the job.

The role of HR managers is to develop employees as they could keep contributing something special for the companies' success. As Rainey et al responded that HRM in the public sector is the development of abilities and the attitude of the individuals, leading to personal growth 
and self actualization, which enables the individual to contribute to organizational objectives (Rainey, 2003, Keating \& Davis, 2000, Caiden, 1991). There are many managers who have different roles in the organizations. This means that Marketing managers care about marketing activities, Finance managers are in deep thought of putting organizational money in the best possible project, IT managers are busy in identifying efficient information systems for smooth workflow automation while HR managers are focusing to entice best people for the organization. But all the managers attain human skills which may or may not be utilized. As far as HR managers are concerned, these human skills are widely evaluated and learned to maintain good environment in the organization. We need talented people and human skilled workforce. Currently, the consistent change in the nurture of HRM is mandatory in organizations. Every company increasingly depends on knowledge, process, management skills, technologies, information about customers, suppliers, old-fashioned, experience and intellectual capital (Fukuyama, 1990). The increased competitiveness puts on added pressure on the need for human capital and a highly committed workforce.

HRM is considered as the mind of a business but employees must justify the benefits and put efforts to achieve organizational goals. Not a single professional, not even those with top qualifications, can be considered human capital unless they contribute to value creation and thus justify the investments of the company (salaries, bonuses, taxes, training, and motivation programs) - Handbook of IC Management in Companies (page \# 29).HR functions must be aligned with the effective use of employees as per organizational demand and employees' expertise. HR functions should be in a real relationship with employees and employers. This research proposed a CMP model that maintains systematic approach of HRM functions. As Pynes suggests "HRM is the design of formal systems in an organization to ensure the effective use of employees' knowledge, skills, abilities, and other characteristics (KSAOCs) to accomplish organizational goals" (Pynes, 2009, 3). This broad definition is supplemented with some specific HRM functions such as "recruitment, selection, training and development, compensation and benefits, retention, evaluation and promotion of employees, and labor-management relations within an organization" (Pynes, 2009, 3).The CMP Model will also portray systematic use of employees and mention good relationships in the organization. The company needs to have proper planning for maintaining good discipline, culture, change\& management style. The CMP model will help organizations to plan and become more disciplined. This will help organizations to identify external factors and utilize internal talents. As suggested by Klinger \& Wool ridge, the functions typically carried out by human resources departments are "planning, acquisition, development, and discipline" (Klingner, 2009, 3). Peggy Jackson (2007) and Blue Wool ridge (2004) indicate that strategic plans should include: an organizational profile to present relevant information about operations, history, success enjoyed, challenges faced, and applicable statistical data; environmental scan and analysis to identify external factors that must be considered and project what the future holds for these peripheral elements. Such planning is a must if companies are to face HR related challenges. The proposed model will help organizations to be more systematic and create a knowledge based working environment. Knowledge workers are defined as workers that possess great capacities in problem solving as well as production of knowledge that requires high level of intellectual capital in a form of specialized tacit knowledge (Mitchell \& Meacheam, 2011) Knowledge workers are always valuable in the identified environment. The development, focus \& change side of the CMP model will help in building intellectual capital and sustaining a good working environment. 
Learning increases human capital (Lazear, 1998), therefore organizations have to engage their workers in training and development because of the rapidly changing working environment (Wild, Griggs \& Downing, 2002; Beaver \& Hutchings, 2005; Ong \& Lai, 2006; Griffin, 2011). The HRD side of management practices \& quality ensures good environment and capable workers. It helps organizations train, help and attain a sense of responsibility. This system will help employees identify their key roles. As suggested by Turkel \& Kline, The Quality Management System suggests that employees have a sense of responsibility and perform their actions by themselves without having to be told (Türkel, 1998:41). The quality management system seems to be significant especially for HRM applications (Kline, 2002:73).

The changing environment of modern companies has changed the role of HRM in the companies. The CMP model explains the role of HR with reference to competitive advantage. It is aligned with planning, development and communication. As Schuler \& Hansen suggested, HRM plays active roles in providing competitive advantage in many changes such as new competitors, new technologies, and reconstitution of works (Schuler, 2000: 240). HRM should overcome problems confronted with the expanding of the field related to human work in new competitive atmosphere (Hansen, 2002: 516).

If CMP model is properly applied then problems and crises can be solved. As identified by Tutar, the most important provision of resolving the crisis is seeking a solution depicting solidarity among employer, employee and even customers (Tutar, 2007: 119).The model is one of the strategic HRD directions to control and maintain the smooth system. It will help and empower employees to better perform in this competitive world. Philosophers like Chung \&Hertog suggested similar arguments. Strategic International Human Resource Management (SIHRM) focuses on conformance to macro perspectives as a strategy, a system in order to control and manage multinational companies' overseas operations in an efficient way (Chung, \& Beamish, 2005: 333). HRM should concentrate on authorizing employees in job processes to play key roles and up skill them (Hertog, Iterson, \& Mari, 2010: 17). The proposed model will help companies perform in better ways. The companies that are sampled in this case study have applied such practices and can serve as examples. HRM and HR managers' role is the backbone in global companies today. "Aspects such as trade liberalization and globalization of markets and industries are not issues that can be viewed just for profit maximization, satisfying customer needs and creating a niche or market position (Sparrow et al, 2004). As all these mechanisms have a direct and profound impact on the behaviors, attitudes and mindsets of people who work in such organizations and on how they should be managed, all these changes and fluctuations have changed the world of work globally" (Deepika Faugoo, Global Cooperation in Management, 2009).

The role of HR managers in such activities has become important and companies need to invest enough money to attract talented HR personnel. HR managers are the attractive icons who can build trust among the employees by collaborating and guiding the employees in various domains. They keep up with the pace with the changing management practices and keep innovating ideas for the betterment of the organization.

Global HR managers or local HR officers, both have the utmost requirement to help people to change attitude towards work and organizational development. "The belief is emerging that the world class human resource (HR) competencies, and the processes for managing them, are those strategic assets that can lend an organization added value over their competitors" 
(Khandekar et al, 2005). HR managers' aptitude develops employees' aptitude enabling them to change their attitude towards organizational success. The HR professional is viewed as the individual who is responsible for identifying and bringing together the right people in order to achieve the organization's strategy. These responsibilities, in addition to the demands placed by the fast-paced business environment, leave few opportunities for mistakes. Therefore, it is crucial for the HR professionals to understand the responsibilities of his or her role within the organization. According to Lawler (2005), the time for HR to change its role and function within the organization is now, as human capital is considered a competitive advantage and HR is the means to leverage that capital. As a result, the HR role must evolve into a business and strategic partnership with the organization to best serve its need. These days organizations are busy in enticing the workforce and motivating them with different methods as this becomes a policy architecture for all the companies as mentioned by Joegensen, B.,2005, "Attract, retain and innovate: a workforce policy architecture adapted to modern conditions", Foresight, Vol.7 No.5, pp. 21-31. As previously mentioned, historically HR has functioned as the traditional entity that offered basic administrative services with an "emphasis on resource efficiency and service quality"(Lawler, 2005).

\section{Changing HRM Practices}

The changing management practices are focused on many areas but three are most dominant where HR managers can contribute their role in modern organizations: The Changing Market trends, Intellectual Capital and Required Technology. CEOs around the world have the same concerns to survive in today's modern organizational focus. "The market is so dynamic. Visibility is very low" says the Electronics CEO, "We are making acquisitions for the people, not the assets" reports the Financial markets CEO, "Technology is driving huge changes in our industry landscape" reflects the Government health agency leader (IBM Global CEO study: The Enterprise of the Future, 2008, page 16) www.ibm.com/enterpriseofthefuture.

The Role of HR managers in such situations is very clear and the need to work on all three areas like Market trends, Intellectual Capital and Technology is quite evident. The HR personnel can play a role of coordination with Finance, Marketing, IT and other departments. HR officers need to come up with the acute interesting models with high tactics to install innovative business models to attract the market. "When the Business Model is innovative, operations and the product will follow automatically" (IBM Global CEO study: The Enterprise of the Future, 2008, page 53) www.ibm.com/enterpriseofthefuture.

The modern companies' biggest practice regarding change management after the year 2000 was to focus on the talent who can design striking strategies to maintain the organizational image. The talented workforce can bring and contribute something very special for the development of company. "Recruiting and developing talented staff and synergizing their contribution with the resource bundling of the firm, can lay the basis for sustained competitive advantage" (Khanderkar et al, 2005). Technology is an area where the HR role has become very crucial. The main responsibility of the HR professional is to be connected with the workforce around the world in just seconds which has saved company's millions of dollars of training \& development. Furthermore, the HR role has been supportive towards managing the workforce very effectively not just monitoring them butguiding, supporting, and motivating them by identifying key competencies and matching them to the right job. "Management of people is increasingly being considered as one of the key links to generating a competitive advantage. Competitive 
advantage leads to organizational effectiveness" (Lengnick in Khanderkar et al, 2005). Such initiatives will definitely bring out the competency levels of the employees and provide a competitive edge to the organization as well.

\section{Changing Management Practices Model (CMP)}

Many philosophers have subscribed to many management styles and work methods in organizations but it always differs from company to company. The literature shows that companies follow different management styles in different cultural context. Some management styles are suitable in European countries while others would be better suited in the Asian environment. Literature shows that some management patterns like business, paternalistic, professional or participative management styles are suitable in various environmental contexts but exploring them based on how much time the companies has to implement it is crucial.

CMP (Changing Management Practices) model is designed to lead companies in the modern domain. The model is based on the following elements (it is applied on the sampled case companies later). This evaluates the Role of HR managers in changing management practices with reference to modern organizational domain. This model suggests that the best way to lead a company is to adopt five basic parameters as setting a culture, bringing a change, developing analytical approach, focusing \& coping up with information economy trends and proven management styles. The CMP model is sequential towards success. All the top companies which are leaders today are only successful because they followed these sequential steps mentioned in the model. Whenever, we mention any successful company, we either mention its culture that ensures everything to be aligned as planned, or mention its change program that transformed employees to apply a hundred percent effort for the company's image, or mention that the company has a great analytical approach because of its human capital where all employees justify their rewards \& put in required working hours.More often than not, the company usually has the best IT setup that makes it number one when it comes to reaching customers with care \& solution.Furthermore the company has a proven management style as it is required as per the need of the hour.

Setting a culture is the tradition of top companies and is initiating a focused care for employees and similarly for customers. However, the culture being determined is not a predictor of excellent performance. Major changes may be required at some point in time. It has been proven that employees become more analytical if given required orientation. This discipline should be highly supported by focusing on essential information regarding economic trends. Lastly, adopting the style that is most suitable for the environment in the company is essential for efficiency. 


\section{CMP (Changing Management Practices) Model}

\begin{tabular}{|l|l|l|l|l|}
\hline \multicolumn{5}{|c|}{ Application on all modern organizations to evaluate the Role of HR Managers in } \\
Changing Management practices
\end{tabular}

Figure \# 1 (CMP model)

\section{Setting a culture}

- Working culture

- Customer focus culture

- Business mind culture

- Caring and helping culture

- Working ethics culture

\section{Bringing a change}

- Why change?

- What change?

- Sensing the results after change

- Careful selection of change agents

- Apprise people that change is beneficial \& make it rewarding.

\section{Developing Analytical approach}

- Market analysis

- Competitors' analysis

- Changing preferences analysis

- Analysis of current and future strategies

- Government analysis \& policies settlement 
4. Focusing and coping up with information economy trends

- Focusing on IT infrastructure

- Focusing on faster electronic trends and usage

- Focusing on IT flexibility for customer usage

- Focusing on customized ERP modules

- $\quad$ Focusing on required IT training for employees

\section{Proven Management styles (Modern and Situational)}

- Professional

- Paternalistic

- Situational

- Equity patterns

- Counseling, Training\& Mentoring

\section{Application of CMP Model on the sampled companies}

\section{AMERICAN COMPANIES}

\subsection{Microsoft}

\subsubsection{Setting a culture}

Microsoft is one of the leading software companies and has a unique, focused working culture. Its employees adopt a very casual culture during their working hours. They keep working wherever they may be ranging from sitting on the walls, tables, the cafeteria, the office, to the staircase. Its focus has made Microsoft successful. Microsoft considers its customers as the most important partner of the company. Microsoft's unique product offerings are the sign of a customer focused approach and this complements its business minded trends. Microsoft is a major player in IT industry which follows its work ethics and legal requirements to the bone, may it be with customers, employees, suppliers or even competitors.

\subsubsection{Bring a Change.}

This company brings change in every aspect of its work because it knows how to cater the changing needs of the customer. Microsoft has implemented such changes and has always been successful. Microsoft's abilityto come up with new operating systems so frequently has the world anxiously waiting for its products. It has an ability to grow because it possesses the sense of identification for what the consumer requires and needs. Microsoft is very good at hiring people and select the best HR personnel who train other employees to be change agents for Microsoft.

\subsubsection{Developing Analytical Approach.}

Microsoft is an authentic company when it comes to reading industry attractiveness. They use out of the box in strategies which brings them in a better position than its competitors. Its success is mainly dependent on knowledge of changing preferences of customers; they evaluate and deliver the right thing to the customers, at the right time. The company is very competent in analyzing future markets and coordinates with government regulations. Microsoft's HR department is an expert at analyzing international markets and then incorporating that analysis within the company to become more competitive. This strategy is known as outside-in strategy. 


\subsubsection{Focusing and Coping up with Information Economy trends}

Being an IT company and in a much better form than its competition, it has an impressive IT infrastructure, competing with many IT giants inside and outside America. It is the market leader to provide flexible and customized software solutions for efficient use in offices and homes as well. It has provided some ERP modules which are customized and has trained its employees diligently and provides guidelines for customers as well to ensure user friendliness.

\subsubsection{Proven Management Styles}

Microsoft has maintained professional management style since decades. They are flexible in the kinds of management styles employed and have instilled in their employees the same kind of rigor. The employees work on their own and are used to ambiguity and uncertainty.

\subsubsection{International Business Machines (IBM)}

\subsubsection{Setting a culture}

IBM is a well established company and is popular amongst its corporate and general customers.IBM is the only company which has formalized itself as a company and has well dressed, high on corporate ethics and hundred percent hard working employees.. IBM employees know what to do at what time. It seems that at IBM its employees are naturally programmed work in any kind of culture. This kind of culture has promoted the customer focused aspect in its employees as well. IBM possesses very impressive business minded personnel as proved by the fact that they keep offering new updates on an IBM gadget and other multimedia \& supportive aids for corporations. . IBM not only trains their own employees but like Microsoft, also helps\& guides customers so that they have total understanding of the product.

\subsubsection{Bringing a change}

Most of the companies always claim that change is important but very few can implement and prosper after a change has been introduced. IBM is the only company which fulfills all claims made to customers, government and employees as well. Change is important at IBM to face and stop the competitors to win the race in customer satisfaction. The change which IBM brings all the time is customer delightedness in novel ways. To keep updated on customer preference \& knowledge, IBM keeps contacting them from time to time. Now-a-days, IBM is changing methods of workflow automation, customer database updates and is finding new ways to keep the company's reputation out of the black water. IBM knows that making changes to customer database will bring in good results and has therefore followed this many times. IBM's HR managers are talented especially in the role of change agents. The role of HR managers has been crucial in making IBM successful. The change has never been resisted at IBM because of the impressive role of HR managers to motivate and inform the employees about the benefits of change about to come.

\subsubsection{Developing Analytical approach}

IBM's varied ambassadors are known as great analysts in the HR, marketing, finance and IT departments. They have a watch on market changes $\&$ updates to foster change management in the company. They focus on competitors' analysis and strategize on how to avoid letting competitors take business from IBM. IBM's strength today is the sense of the changing preferences and the analysis that follows. The employees receive formal trainings for such 
analysis. They are also experts in knowing the current \&ever so dynamic markets with reference to the laws, regulations and government policies

\subsubsection{Focusing and coping up with information economy trends}

IBM is an expert on focusing on IT infrastructure. In fact, IBM is the world's leader in IT infrastructure which provides corporations with faster electronic to accelerate business transactions and keep connected with the rest of the world. It provides varied customized ERP modules and other software and machines for the requirements of these customer corporations. IBM is the leader in such areas since many years and that can be attributed to its trained employees and HR personnelwho coordinated with other departmental managers.

\subsubsection{Proven Management styles (Modern and Situational)}

IBM follows almost all management styles to be flexible and remain updated with the requirements of the changing trends of corporations and customers. IBM follows professional style management and teach sits employees the essence of such management practices. . IBM employees are not only focused on companies' requirements but also put more efforts than required, this whole kudos goes to HR people who guided and trained in such manner. The professional style of HR managers play very vital role in equipping employees on company objectives and its image.

\subsection{Google}

\subsubsection{Setting a culture}

Google is one of the top American brands in the "search" domain and has been accepted as the search leader in the world. People love Google for its search offerings and quick services in information handling pools. Google, no doubt, has a very impressive and customer focused approach which definitely is a proof of success. Google is less business minded as they claim to be and is more concerned about customers.

\subsubsection{Bringing a change}

Change is the permanent activity at Google as it comes up every time with new offerings because they want to focus on their customers. Customers feel more than happy at availing new benefits offered by the company. Google is also efficient in hiring talented intellectual capital which helps it develop and understand the results of the change activity. Their employees are always well aware of the imminent change and this can be attributed to effective and clear communication .

\subsubsection{Developing Analytical approach}

Google provides employees an opportunity of training and independence as well as opportunities to come up with good ideas for the company. They are experts in market analysis and competitors' analysis and focus on the changing preferences of customers, government, suppliers and competitors. Being on the search of good things for customers, Google forms teams to conduct an in depth analysis current and possible futuristic change that may happen in IT and other search domains. That team including HR managers become active and show utmost responsibility in maintaining Google's number one position.

\subsubsection{Focusing and coping up with information economy trends}


As Google is an expert in software search, competitors come up with supportive IT infrastructure. Google focuses on such trends which may help Google maintain its lead position. Google's focus on customized search engine facilities is no doubt, helping corporations to know and share the information with the rest of the world. Google's facilities with IT flexibility create training opportunities for Google's employees to be more updated and up skilled.

\subsubsection{Proven Management styles (Modern and Situational)}

Google follows all management styles because it maintains a situational trend which they believe is the most effective in today's business world. Google follows different management styles time to time but professional is dominant as Google's employees are asked to adapt to such a culture from the minute they join the company.

\subsection{General Electric (GE)}

\subsubsection{Setting a culture}

GE provides a platform for the employees to work on customer focus in a business minded culture. This means a business is important but employees, customers, government and suppliers, all are equally important. GE Managers think along the lines of contributing more to the country rather than to business needs. It provides and promotes caring and ethical culture on a larger scale. Its employees are very happy and hold their top management in high regards. This credit goes to JeffImmelt or Jack Welch (ex CEO) for maintaining such a unique working culture at the company.

\subsubsection{Bringing a change}

The company brings changes which are helpful in working efficiently every year. The biggest change in this year $\mathrm{t}$ was the coordination with employees, understanding their concern about presentation of the company's projects and new products which can make company even more reputable. This has happened through talented HR managers who identified the right change agents in the company and brought numerous of positive ideas to the table. This only happens when employees are given total information about change, implementation and promotion opportunities.

\subsubsection{Developing Analytical approach}

GE is focused on market and competitors' analysis but also has trust on its potentiality to maintain the position. They focus on which changes are imminent ahead and how to come up with policies to navigate through them. GE's unique marketing strategies have earned better government policies and settlements. It has unique tools to explore and keeps a keen eye on current and future strategic analysis.

\subsubsection{Focusing and coping up with information economy trends}

GE focuses on required IT information which helps to coordinate and accelerate working efficiency at required demands. They have a good IT set up but do not opt for fancy electronic setups as it is not a business requirement. It has customized ERP vendors by which they coordinate and collaborate with government, suppliers, customers and employees as well. GE uses Information Technology in training the employees sometimes as well. It has a good focus on required trainings for some technical aspects. 


\subsubsection{Proven Management styles (Modern and Situational)}

GE focuses on equity patterns, professional \& situational management styles. GE believes that equity patterns are the most demanded \& supported kind of management style by its employees. GE is also following professional management style where all the employees behave and work as required by the company. It also has a vast pool of counseling sessions but do not indulge in a lot of trainings as they believe that their employees are absolutely talented in their areas and training is not the need of the hour.

\section{$1.5 \quad$ Coca-Cola}

\subsubsection{Setting a culture}

Coca cola is a very successful company and is very popular amongst its customers due to its way of working and customer focused culture. The company has a very business minded culture and has proved to be number one in beverages business and stood out as a giant wall for other beverages competitors. Coca cola believes that their employees are trained by HR managers to achieve company's' objectives.

\subsubsection{Bringing a change}

Introducing varied products is the biggest change Coca Cola has come up with. They change because of the changing preferences \& changing behavior of customers and offer unique packages so as to retain them. This is possible through the efforts of marketing managers and HR managers who select the change agents very carefully and provide them with the required information and a sense of belonging to the company. Coca cola's strength ins motivating employees and convincing them that they are the most important icon of the company.

\subsubsection{Developing Analytical approach}

Coca Cola managers are very analytical and that is the reason, the company is enjoying such an over whelming response in specially in North \& South American, European \&Asian region. It is serving the world with the finest beverages which no other company has been able to offer and this has been made possible through the market analysis, competitive analysis, changing preferences and futuristic focus of beverages business. Coca Cola's HR managers have a very unique collaboration and rapport with government officials which works out well in their favor.

\subsubsection{Focusing and coping up with information economy trends}

Coca cola is maintaining all required information on economy trends especially its customized ERP modules which helps in coordinating with the employees, dealers, suppliers and customers in particular. They require only customized and flexible IT domain for the smooth working styles to be connected and remain updated with the changing patterns of other companies. Employees are highly trained in the marketing, IT, finance and HR domain to cope up and keep up the pace with fast changing technological advancements.

\subsubsection{Proven Management styles (Modern and Situational)}

Coca cola maintains a high profiled counseling, situational and participative management style for the purpose of maintaining and creating cordial atmosphere at the company. The company maintains professional management style which helps employees to be more committed to the work 


\section{ASIAN COMPANIES}

\subsection{Toyota}

\subsubsection{Setting a culture}

Toyota is one of the leading companies from Japan and has millions of customers all around the world. The company believes that employees own the company. This is the only company who initiated an idea of sense of ownership. At Toyota, employees are motivated to the extent that they say, "we don't work for Toyota, we are Toyota". Toyota has strong customer focus as well. They help customers in various ways and this has helped Toyota earn business around the globe.

\subsubsection{Bringing a change}

Toyota brings change only when they get a signal from the customers. They do it through the support of HR managers and marketing managers to gather evidence regarding customer opinions and after that they select the best workforce. Marketing and HR personnel always think of changes which should be better than competitors. Toyota, being number one in sense of ownership always apprises employees about all the things that happen in the company.

\subsubsection{Developing Analytical approach}

Toyota's analytical managers have always sensed the market potentiality and competitor's possible strategies and have suggested for better strategies for Toyota. It focuses on current and futuristic happenings and that has made the company very successful. The company maintains a very cordial relationship with government efforts, customers and other important public members which are directly involved in the promotion of the company.

\subsubsection{Focusing and coping up with information economy trends.}

Toyota focuses on similar IT systems as other companies do follow in the same domain. Toyota uses technical support for the purpose of manufacturing plants where robotics is required. The company also uses high IT systems which are required to coordinate and consult with HR, Marketing and other employees of the company. It has a very flexible and customized ERP module that reaches the customers, government and employees in particular.

\subsubsection{Proven Management styles (Modern and Situational)}

Japanese companies always follow parental and caring management style and Toyota follows the same but also uses some other styles such as participative and professional. Such a system and style keeps changing from country to country as cultural contexts vary.

\subsection{China Mobile}

\subsubsection{Setting a culture}

China mobile is focused on its vision \& profitability. It has a very successful and disciplined culture at work, professionalism and a sense of ownership with the company. Company's profitability vision shows its business mind culture but this company never compromises on quality. The customers of China Mobile have a conviction about the quality and care for the company's products, promotions and unique services. The customers are frequently asked about the services and products to keep up to date with the current and futuristic trends. 
China mobile has given a tough time to its competitors. It maintain sigh ethics in all areas of business and keeps a check on operations from time to time.

\subsubsection{Bringing a change}

China mobile's biggest change is that the company diversifies in to different countries. They bring the change according to different cultures of the countries. China mobile also has programs for corporate social responsibility, such as providing free airtime, collecting abandoned batteries, and sometime providing help to government and customers. The company maintains good rapport with the government.

\subsubsection{Developing Analytical approach}

China mobile is always on the hunt for a pool of talented workforce at the company. China mobile staff is very analytical, innovative and good at developing work strategies to beat the competitors. The most important strategy of their managers is to intimidate competitors by designing ways that the competition cannot imitate. China mobile always wins the race over the competitors.

\subsubsection{Focusing and coping up with information economy trends}

The company does not believe in IT systems but still has the best IT systems placed in the company. The company has such systems installed to coordinate and be connected with customers and employees. The company takes initiatives for the employees to cope up with customers in a flexible manner to maintain the company's image. The company also trains its employees using technological interfaces.

\subsubsection{Proven Management styles (Modern and Situational)}

At China Mobile, they maintain a professional management style which shows everybody's responsibility is clearly defined and shared with the employees which prove the company's success. For this reason, all the employees not only have a focused approach but also minimize the wastage of company's resources.

\section{$2.3 \quad$ TCS}

\subsubsection{Setting a culture}

TCS focuses on customer database and designs strategies to achieve business minded activities in all domains. The company is very responsive to customers. TCS is a very ethical company and has shown utmost care and guidance for its customers. All divisions are working smoothly and the workforce is satisfied with the company's position.

\subsubsection{Bringing a change}

TCS has maintained the change processes in a varied format, sometimes particularly done for the customers, sometimes promotion fairs for employees, and sometimes, best services, quality products, timely delivery and much more were kept as the main focus. TCS has a work force which is very motivated and hard working. The HR managers always select good people to train the employees and guide them to achieve company objectives. 


\subsubsection{Developing Analytical approach}

TCS managers are talented and analytical in identifying their competitor's plans. They launch good promotion schemes before the competitors hence are quite proactive. TCS has an accurate focus on understanding the changing preferences of customers as it offers packages for students and special packages for Eid, Valentine's Day and other such festivals. TCS focuses on every aspect of current and future to maintain its reputation as the leading courier service of Pakistan. TCS follows all regulations identified by the government.

\subsubsection{Focusing and coping up with information economy trends}

TCS has maintained a very accurate and apt IT system and has implemented a very high ERP module as well as other IT systems to keep track on the customer shipments and coordinate with customers and employees. TCS also has a strong IT system to coordinate with different embassies for passport delivery services.

\subsubsection{Proven Management styles (Modern and Situational)}

TCS follows a participative management style which gives more confidence to TCS employees. Such sense of recognition and ownership to employees makes them more motivated to come up with innovative ideas for achieving company's success. TCS also follows some other management styles based on situational requirements.

\section{$2.4 \quad$ Airtel}

\subsubsection{Setting a culture}

Airtel has an impressive culture of working. It is customer oriented \& business related in nature. Airtel is a very business oriented company and has helped India with increasing the number of jobs available, offering good products to the customers and is popular for its ethical communication system.

\subsubsection{Bringing a change}

All companies bring changes but Airtel faced a major structural change when they merged with Google to give their customers better options. . Airtel is expert in sensing the results and this helps them get a larger chunk of the market. Airtel believes that the credit goes to the marketing \& HR managers for giving understanding the business to such depths and helping the company succeed.

\subsubsection{Developing Analytical approach}

Airtel is very successful in India and has a very clear vision and focus on the market potentiality. Its competitors are working very hard to beat Airtel but have failed in front of very proactive approaches of Airtel. Airtel has earned much respect in Asian market and continues to do so because of its HR managers' innovative market readings in current \& futuristic domains. Airtel also maintains good coordination with the respective governments in terms of their policies.

\subsubsection{Focusing and coping up with information economy trends}

Airtel has focused on IT flexibility which is demanded by the customers. Airtel has acoordinated and customized IT network set up which helps Airtel to connect \& have flexibility. 
Airtel has proven to be very responsive in training the employees for understanding Airtel's future plans.

\subsubsection{Proven Management styles (Modern and Situational)}

Airtel follows participative management style in which they recognize their employees and and this in turn helps employees put in more effort in order to grow with the market. Airtel's HR managers believe that the participation style of management has become very successful at Airtel.

\section{$2.5 \quad$ SingTel}

\subsubsection{Setting a culture}

Singapore Telecom is one of the leading companies in the telecom sector and has earned a lot of respect due to its culture. It has a versatile business approach in which customer care and guidance is imperative. The workflow in SingTel in highly standardized keeping the employees motivated where they feel as if they own the company.

\subsubsection{Bringing a change}

The company brings in change to motivate the employees to help management achieve the company's successive position. The HR managers possess the talent to sense the imminent threats and opportunities for the company and help to coordinate with the marketing and finance department to smooth the work process. HR personnel help the company to select the right people who fit perfectly for the job.

\subsubsection{Developing Analytical approach}

The company has collected the talent from every corner of the world to create and innovate in strategies for the company and this is the reason that the company has maintained a very good reputation in the minds of the customers around the world. They always update themselves with the changing preferences of the customers. SingTel has a very stalwart support from the government to implement their practices for the local and international customers.

\subsubsection{Focusing and coping up with information economy trends}

The company is equipped with the world's best IT systems to reach customers in order to coordinate with service packages. It has the best infrastructure, innovative ERP modules for smooth working conditions and accelerated workflow automation. Employees are trained in many domains which are concerned with the company. SingTel is number one in identifying the needfor training and systems for the customers.

\subsubsection{Proven Management styles (Modern and Situational)}

SingTel maintains equity patterns and parental management style which is more towards independence of the employees. SingTel believes that its employees are highly Trustworthy and this has helped them achieve profitability for the company

\section{Comparative Analysis}

Comparatively, all sampled companies follow similar strategies in most of the cases. The companies' HR managers have reported that HR managers' roles in changing management 
practices are very important at all levels of the organization. The overall response was very positive and HR managers supported all questions asked with positive opinions. On the basis of such analysis the CMP model was generated to check the role of HR managers in changing management practices with special reference to different categories mentioned in the model.

Training is one of the strategic HRD tools which companies are using these days. Training enhances the performance as indicated by Saks in 2002. The model has also covered some aspects of training based on its importance in modern companies. Microsoft has followed it for understanding customer needs but in a competitive way, IBM has followed it by keeping a futuristic vision, Google has followed it by making sure it is the only one providing something very unique, GE has followed the customer \& employee centered approach to keep everything intact while Coca Cola has followed an approach that reaches the customers and consumers in a novel way.. The last category environment is the Asian context where China mobile used the model to entice customers with the best quality \& service. In a similar fashion, AirTel and SingTel have done a lot for the customers and employees. AirTel has provided all modern and state of the art technological systems to customers in India and abroad while SingTel has maintained its customer database very effectively and is still growing where they have adopted the bankable opportunity and approach. Toyota is a different industry category but the sense of ownership towards the company is the most successful approach as proved above. TCS has applied the model from all aspects to bring success to the company and the employee centered approach remains very successful. Finally, research found that all of the above strategies and approaches were very dependent on the role of HR managers in current environment and forthcoming situations.

\section{Research Methodology}

The study is primarily on the field of HR, its changing management practices and modern organizations which are identified in the selection of companies in this case study paper. The research is purely basic \&the case study methodology was adopted. The results are explained from the structured \& unstructured questions asked from the managers. To conduct the research on such companies in varied formats, qualitative case study approach was the best option and this remained fruitful after collecting the relevant information to serve the purpose of the research. On the basis of such approach, CMP model was developed and introduced and applied on the sampled companies in this research. Through this methodology, the basic and exploratory objectives of this particular research are achieved. As Strauss \& Corbin argued that a qualitative approach is particularly adequate for explorative aims. Van Maanen, 1983:10) "the aim is directed towards increasing the contextual understanding which implies the qualitative assumption that the research need to gain more or less intimate knowledge of a research setting (Van Maanen, 1983:10).

All the companies mentioned in this research adopt the modern and new mandate for human resources which is quite credible as mentioned by Ulrich, D.O.,1998, "A new mandate for human resources", Harvard Business Review, Vol.76 No.1, pp.124-34.The purpose of this research is to investigate the role of HR managers in changing management practices which is based on the functions and roles of the managers. For this purpose, an exploratory and a qualitative case study method is appropriate to understand the role of HR managers in CMP model. 


\section{Limitations}

Few limitations came across from the response of some companies but after repetitive visits, telephone calls, emails to authorities, review of literature survey and exploration made it possible to collect enough information to meet the objectives. This made the response satisfactory and helped in the collection of relevant data. While sending out emails and conducting telephone calls, a major challenge faced by the research team was of delay but persistent reminders made it possible to get the response on the time.

\section{Case Findings \& Recommendations:}

This case research has found that proposed functions in the CMP model will be beneficial for the companies who want success in modern paced time. The proposed functions were evaluated and applied at all companies mentioned in the research. This comparative case study found that companies want to adopt CMP model as it is less complicated. After the findings, following recommendations were also added:

- $\quad$ Since time, technology, diversity \& change push companies to stiff competition, the companies must adopt the proposed model and analyze it with technologically based system in the organization. Organizations should specifically follow and train high level staff as they can later be oriented to other staff members.

- $\quad$ The proposed CMP model should be a benchmark for the companies that are stuck with the all too familiar HR issues at the moment. Companies in any country can benefit from such a model and translate it according to the requirement of the company or culture.

- $\quad$ The study recommends that HR managers should be involved at all levels of management functions to identify the talented manpower and guide them to achieve organizational objectives with special reference to modern approaches.

- $\quad$ Modern Organizations are using many management styles which are situation oriented in nature and HR managers play an important role in coordinating with other managers to keep an eye of organizational developments .The study submits further recommendations of understanding modern management practices of evaluating competitors' success and predict the processes which competitors have adopted and been successful in.

- $\quad$ Finally, HR managers' role is not only to carry out required activities but to keep exploring more innovative ideas to support companies.

\section{Conclusion}

Organizations are in great search to hunt intellectual capital which is not easily accessiblebut HR professionals and their role has made the organizations fill such hiatus through accurate and modern training for employees. The major purpose of this training and development is saving companies from big losses. The study concludes that organizations need to be cautious in selecting models, framework or any analysis to bring required development. The model like CMP is the easiest and flexible to bring required change to move towards success. The role of the HR managers needs to be understood and generalized to other departments as well. The research concludes that HR managers favor technological updates to accelerate coordination and provide flexibility to employees in workflow automation and help customers to be in touch with the company at any time. The study has submitted that HR managers mostly believe that the function of HR has increased in scope and responsibility in Multinational Corporations and also believe that playing an important role as a change agent in modern organizations is equally important. 
Most of the HR managers of modern companies mentioned in this research supported that the role of HR managers will keep changing in future. The proposed CMP model will generally be compatible with all forthcoming changes in modern companies.

\section{References}

AbergAas, (2005) "Even HR departments are downsized, HRM seems to become increasingly important"

Joegensen, B.,2005, "Attract, retain and innovate: a workforce policy architecture adapted to modern conditions”, Foresight, Vol.7 No.5, pp. 21-31

As Devanna said "HRM is very important thing, its areas as suggested (1984)

Armstrong (2000)

Klingner, Donald E. 2009. Competing perspectives on public personnel administration: Civil service, patronage, and privatization. eds. Steven W. Hays,

Richard C. Kearney and Jerrell D. Coggburn, 3-16. New York: Longman.

Pynes, Joan E. 2009. Human resources management for public and nonprofitorganizations: A strategic approach. 3d ed. San Francisco.

Woolridge, Blue. 2004. Preparing public administrators for an era of globalization and decentralization: A strategiccontingency approach. International Review of Administrative Sciences (70): 385-403.

Saks, A., S. Taggar and R. Haccoun .,2002, International Alliance for Human Resources Research, Vol. 6, No. 3, Fall 2002, 5 p.

Beer "Managing Human Assets (Beer, et al, 1984)

Khanderkar et al (2005)

Ulrich, D.O.,1998, “A new mandate for human resources”,HBR, Vol.76 No.1, pp.124

Lengnick in Khanderkar et al (2005)

Peggy M. 2007. Nonprofit strategic planning. New Jersey:

Callahan, J.S., Kiker, D.S., \& Cross, T. (2003). Does Method Matter? Analysis of the Effects of Training Method on Older Learner Training Performance. JOM, 29 (5), 663.

Mitchell, R. \&Meacheam, D (2011). Knowledge worker control: understanding via principal and agency theory. The Learning organization, 18(2), 149-160.

Tan, F.M. (2008). Organisational Support as the Mediator of Career-Related HRM Practices and Affective Commitment.

Wild, R.H., Griggs, K.A. \& Downing, T. (2002). A framework for e-learning as a tool for knowledge management. Industrial Management \& Data Systems, 102(7), 371-380.

KLINE, J. J. (2002). The Development of Human Resources Management in Quality Award Winnings Governments. Journal of Organizational Excellence, Vol. 21, Issue 4, 7

TÜRKEL, A. (1998). IşsletmeYöneticileri IçinToplamKaliteYönetimiveİnsanKaynakları. İstanbul: TürkmenKitabevi. 
IBM Global CEO study: The Enterprise of the Future, 2008, page 16 "The market is so dynamic. Visibility is very low" Electronics CEOwww.ibm.com/enterpriseofthefuture

Chung, C. C., \& Beamish, P. W. (2005), Investment Mode Strategy And Expatriate Strategy During Times Of Economic Crisis, JOIM, 11, 331- 355.

Hansen, W. L. (2002), Developing New Proficiencies For Human Resource \& Industrial Relations Professionals, Human Resource Management Review, 12, 513-538.

Hertog, F. D., Iterson, A. V., \& Mari, C. (2010), Does HRM Really Matter In Bringing About Strategic Change? Comparative Action Research. European Management Journal, 28, 14- 24.

Tutar, H. (2007), KrizveStresYönetimi, SeçkinYayıncılı,,

Websites: www.microsoft.com, www.ibm.com, www.google.com, www.ge.com, www.cocacola.com,www.toyota.com,www.chinamobileltd.com,www.tcs.com.pk, www.singtel.comwww.airtel.in,

\section{Acronyms used in the paper}

- $\quad$ CMP (Changing Management Practices)

- $\quad$ HRM (Human Resources Management)

- HRD (Human Resource Development)

- $\quad$ OD (Organizational Development)

- $\quad$ TQM (Total Quality Management)

- $\quad$ BPR (Business Process Re-engineering)

- IT (Information Technology)

- $\quad$ MIS (Management Information System)

- $\quad$ IBM (International Business Machines)

- G.E (General Electric)

- $\quad$ ERP (Enterprise Resource Planning)

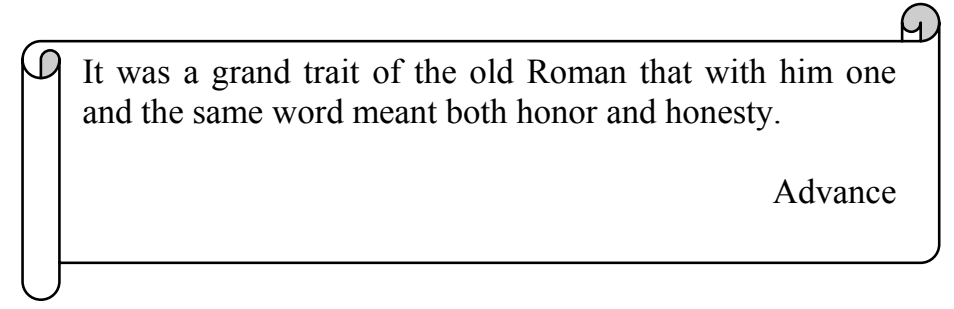

